DR ALICE ARMITAGE MBBS (Orcid ID: 0000-0001-6972-3651)

Article type: Service description and evaluation

\title{
Description and evaluation of a pathway for unaccompanied asylum-seeking children
}

Authors: Alice Armitage ${ }^{1}$, Jonathan Cohen ${ }^{2}$, Michelle Heys ${ }^{1}$, Pia Hardelid ${ }^{1}$, Allison Ward ${ }^{3}$, Sarah Eisen $^{4}$

Email addresses: alicejanearmitage@nhs.net, jonathan.cohen2@nhs.net, m.heys@ucl.ac.uk, p.hardelid@ucl.ac.uk, allison.ward1@nhs.net, sarah.eisen@nhs.net

1. Population, Policy \& Practice Dept, UCL GOS Institute of Child Health, Faculty of Pop Health Sciences, UCL

2. Paediatric Infectious Diseases Department, Evelina London Children's Hospital

3. Children's Services, Central and North West London NHS Foundation Trust and Royal Free London NHS Foundation Trust

4. Department of Paediatrics, University College London Hospital (UCLH)

\section{Correspondence to:}

Dr Alice Armitage

UCL Great Ormond Street Institute of Child Health

30 Guilford St, Holborn, London WC1N 1EH

Tel: 02072429789

alicejanearmitage@nhs.net

Funding: This research did not receive any specific grant from funding agencies in the public, commercial, or not-for-profit sectors. Research at the UCL Great Ormond Street Institute of Child Health benefits from funding from the Great Ormond Street Hospital Biomedical Research Centre.

\section{Acknowledgements}

The authors would like to thank all of the young people whose data is presented here. Material from this article has been presented at the RCPCH online conference 2020 in two oral presentations, as well as several local presentations. Two abstracts have been published in Archives of Disease in Childhood.

Authors' contributions: All authors contributed to the article design. AA carried out the data collection and analyses, with input from JC, MH, PH, AW and SE. All authors contributed to the interpretation of the results. AA wrote the article. All authors commented on drafts of the article and have approved the final version. All authors declare no known conflicts of interest.

Tables: 4

Figures: 1

Appendices: 0

Word count: 2495 
2| P a g e

\section{Abstract \\ Objective}

1. To describe a novel integrated pathway for unaccompanied asylum-seeking children (UASC)

2. To evaluate a population engaged with this service.

\section{Design}

Description of the integrated pathway (objective 1) and retrospective evaluation, using data from community paediatrics, infectious diseases (ID) screening and a sexual health (SH) service (objective 2).

\section{Setting}

Unlinked data were collected from three services across three NHS trusts in London.

\section{Patients}

All Camden UASC engaged with the service from 01/01/2016 to 30/03/2019.

\section{Interventions}

A multi-disciplinary approach prioritising the health needs of UASC including a child and adolescent mental health service (CAMHS) representative and LAC health improvement practitioner. There are low thresholds for onward referral and universal asymptomatic screening for ID.

\section{Main Outcome measures}

Data on demographics, unmet health needs and known outcomes.

\section{Results}


Data were available for 101 UASC, $16 \%$ female, median age 16 years (range 14-17). Physical assault/abuse was reported in $67 \%$ and $13 \%$ disclosed sexual assault/abuse, including $38 \%$ of female UASC. Mental health symptoms were documented in $77 \%$. Infectious diseases warranting treatment were identified in $41 \%$ including latent tuberculosis (25\%) and schistosomiasis (13\%). Interpreters were required for $97 \%$ and initial nonattendance rates at follow-up were $40 \%$ (ID) and $49 \%$ (SH).

\section{Conclusions}

These data demonstrate high rates of historic physical and sexual assault/abuse, unmet physical, mental and emotional health needs among UASC and significant barriers to engaging with services. An integrated pathway has been successfully implemented and shown to deliver appropriate, joined-up care for UASC, consistent with current recommendations, with the potential to improve outcomes. 


\section{What is already known on this topic}

- Migration status is a key determinant of health.

- Unaccompanied asylum-seeking children (UASC) are a vulnerable population with significant social, educational, mental and physical health needs.

- The lack of healthcare data on refugee or asylum-seeking child health has been identified as an unmet research need, as well as a rights-of-the-child concern.

\section{What this study adds}

- To the best of our knowledge, we present the most comprehensive and largest empirical UK data on UASC health needs.

- London UASC have high rates of physical and sexual abuse/assault, and infectious diseases warranting treatment.

- An integrated pathway has been successfully implemented in Camden (London) and has been shown to deliver appropriate, joined-up care for UASC, consistent with current recommendations. 


\section{INTRODUCTION}

There were 5070 unaccompanied asylum-seeking children (UASC) in England at the end of March 2019(1), the majority of whom were male (91\%) and aged 16 or $17(85 \%)(1)$. UASC have frequently suffered trauma, including rape and torture, in their country of origin or during their journey(2), as well as poverty, deprivation and reduced access to healthcare(3). They represent a vulnerable and diverse population with significant social, educational, mental and physical health needs(4).

There is a lack of guidance and education on management of UASC, and no standardised guidance for how their initial health assessments (IHAs) should be carried out(5). The medical staff undertaking assessments, time for appointments, translation facilities, thresholds for onward referrals and multi-disciplinary involvement vary(6). Infectious diseases (ID) and mental health problems are prevalent among UASC(7,8), and management including screening, diagnosis and referral for these conditions is inconsistent. The allocated social worker (SW) bears much of the responsibility for the health care plan resulting from the IHA, but often have limited training on UASC needs and a high caseload limiting their available time and input.

There is a lack of empirical data available on UASC, particularly more recent evidence from the UK(9). The lack of healthcare data on refugee or asylum-seeking children has been identified as an unmet research need(10), and a rights of the child concern(11).

We aim to describe a novel 'integrated pathway' for UASC developed in a London borough, and to present data from a population of UASC engaging with this service over a three-year 
6I P a g e

period. We aim to describe the baseline and clinical characteristics, and known outcomes of a population of London UASC.

\section{METHODS}

\section{Description of the integrated pathway}

The integrated pathway (see figure 1.) for UASC involves a multi-disciplinary approach and prioritises three key areas: physical, sexual and emotional health. All UASC are referred for ID screening and signposted (provided with contact details and empowered to initiate contact with the service) to sexual health (SH) services, regardless of clinical presentation or risk factors. There is a low threshold for Child and Adolescent Mental Health Service (CAMHS) referral, with a clinical psychologist from CAMHS working as part of the team. Mental health symptoms including post-traumatic stress disorder, anxiety and depression as well as risk of self-harm and suicide are considered(12), and the Strengths and Difficulties Questionnaire (SDQ)(13) is used. Standardised referrals are made for vision screening, hearing screening, dental care and catch-up immunisations. A health improvement practitioner works with the team liaising with UASC and the professionals around them (including the SW) to optimise engagement with medical services and reduce missed appointments. Face-to-face interpreters are used whenever possible and appointments are rebooked if necessary to facilitate this.

\section{Study population and period}

The study period was $1^{\text {st }}$ January 2016 until $30^{\text {th }}$ April 2019. Data were collected retrospectively for all UASC in the borough of Camden seen at three services across three NHS trusts: community paediatrics where IHAs took place, the ID clinic to which UASC were referred and a SH clinic within the same borough. The data were unlinked (no patient 
7| P a g e

identifiable information was shared between trusts) and therefore there may be small differences in the group described due to time delays between appointments.

Community paediatrics data included IHA reports and any additional available documentation available, including letters and social care records. Access was via an electronic health record system, SystmOne. A data extraction tool used in a previous audit(14) was revised to include additional detail, and data were entered into an Excel spreadsheet in anonymised form. ID and SH screening data were collected from clinic letters and entered into an Excel spreadsheet.

\section{Outcomes, demographic and clinical variables}

The following demographic data were collected where documented: age, gender, country of origin, use of interpreter and language, type of accommodation, reasons for leaving country of origin, arrival in UK, circumstances of transit (including refugee camps) and contact with family.

The following clinical data were collected where documented: past medical history, physical symptoms, mental health symptoms, history of sexual abuse or assault, history of physical abuse or assault, known vaccination history. Clinical variables including weight and height, examination findings including scars and any signs of infection.

Onward referrals were recorded as were attendance rates at scheduled appointments. Data on outcomes were recorded where available such as results of a review health assessment (RHA) if present, results and completeness of ID screening, results and completeness of SH screening and SH education given. 
$8 \mid$ P a g e

Statistical analysis (calculations of percentages) was performed using Microsoft Excel version 2016.

\section{Ethical approval}

This service evaluation is exempt from formal ethics review under HRA guidance. 
9 | $\mathrm{P}$ a g $\mathrm{e}$

\section{RESULTS}

Data from IHAs were available for 101 UASC; one IHA was completed in absentia. Data were also available from 41 and 69 UASC from the same borough and study period seen at a local SH service and an ID screening service respectively.

\section{Community paediatrics data}

Table 1. shows the demographic characteristics from the IHA data.

Reasons for migration included fear of persecution $(23 / 101,23 \%)$, fearing for their lives following the death of family members $(17 / 101,17 \%)$, fleeing forced military service $(17 / 101,17 \%)$ and fleeing forced marriage $(4 / 101,4 \%)$. It was documented that $43 / 101$ $(43 \%)$ of the young people spent time in a refugee camp, most commonly the so-called 'Calais jungle'. Where information was available, 63/81 (78\%) of UASC reported any duration of formal schooling in their country of origin, and 14/73 (19\%) were currently in contact with their family back home. When the Red Cross tracing service was offered 5/101 $(5 \%)$ of UASC refused explaining that it would put their family in danger.

\section{Mental and physical health symptoms}

Many UASC reported current physical and mental health symptoms at IHA. Common physical symptoms were body or limb pain $(28 / 101,28 \%)$, abdominal pain or gastrointestinal symptoms $(24 / 101,24 \%)$, headache or dizziness $(23 / 101,23 \%)$, chest pain or palpitations $(9 / 101,9 \%)$ and symptoms of current or previous scabies infestation $(11 / 101$, $11 \%)$

Mental health symptoms including symptoms of trauma are recorded where they were documented by the assessing paediatrician. Three quarters $(78 / 101,77 \%)$ of UASC had any 
mental health symptom documented, mostly commonly sleep problems $(50 / 101,50 \%)$, signs of trauma or PTSD $(43 / 101,43 \%)$ and deliberate self-harm or suicide attempts $(8 / 101,8 \%)$.

Rates of physical and sexual assault and abuse, and examination findings are shown in Table 2.

CAMHS input was offered to 88/101 (87\%) of UASC, of whom 20 initially declined, though some later consented to referral. 52/101 (51\%) of UASC were directly referred to CAMHS, and a further 20 were signposted to services. Referral for ID screening is documented for 93/101 (92\%) of UASC and 52/101 (52\%) were referred to sexual health screening while a further 36/101 (36\%) were signposted. 9/101 (9\%) of UASC were referred to specialised services for sexual abuse or assault.

\section{Recorded outcomes}

A RHA one year after IHA was available for 26/101 (26\%). Other relevant documentation from social care or other health services was only available from a minority of young people. There were recorded examples of mental health admissions ( 2 cases), substance misuse (3 cases), police involvement (3 cases), break-down of placements (3 cases) and pregnancies among female UASC ( 2 cases). Commonly cited causes for psychological distress were pending asylum claims ( 3 cases) and the national transfer scheme ( 8 cases), whereby UASC are moved to different boroughs.

\section{ID screening results}

The ID service received 84 referrals for Camden UASC and data are available for 69 appointments, see Table 3. 
11 I P a g e

Only $60 \%$ of UASC attended for their initial appointment, but following attempts to optimise engagement a total of 71/84 (85\%) of UASC underwent ID screening in the service.

\section{Sexual health screening results}

Data were available for 41 UASC who attended a local SH service, (table 4), these data comprise scheduled appointments and walk-ins. There were no positive results for chlamydia or gonorrhoea in this cohort. No new diagnoses of blood-borne viruses were made from sexual health screening (though 4 cases of hepatitis B were diagnosed in ID clinic). 


\section{DISCUSSION}

\section{Key findings}

These UASC demonstrated high rates of physical health problems and mental health symptoms warranting CAMHS referral. Barriers to accessing services and delivering care were demonstrated including inconsistency around names and dates of birth, high DNA rates and requirement for translators. An integrated pathway for UASC has been successfully implemented as a clinical management approach for this complex and vulnerable population.

\section{Strengths and limitations}

Data from three different services provides a comprehensive picture of the emotional, physical and sexual health needs of this population who are not flagged in routinely collected NHS datasets. We demonstrated that the integrated pathway model, in place since 2016, can be successfully implemented in a London local authority. However, the study size was small and limited to a single local area. It was not possible to access data from the NHS trust where the CAMHS service was based, limiting the completeness of this data set. As a retrospective evaluation there was reliance on comprehensive documentation, and data were incomplete for some demographic and outcome measures. In the absence of comparative data (for example before-and-after or between boroughs) we are unable to prove that integrated pathway improves outcomes.

\section{Findings in context}

These comprehensive data from 101 UASC including demographics and health needs are some of the largest contemporary data available on UASC in England. The proportion of female UASC here is higher than the England average (16\% vs 9\%)(1). Otherwise, the age and demographic characteristics are broadly representative of UASC across England. 
Our findings are consistent with data on the health of UASC internationally(2-4, 15-17). Systematic review evidence on screening of refugee children showed intestinal infections in $31 \%$, latent TB 11\%, and hepatitis B 3\%(18). In comparison, Camden UASC had almost double the rates of latent TB $(25 \%)$ and hepatitis B $(6 \%)$, but lower rates of intestinal infection (10\%, not including schistosomiasis). A study of UASC in Kent in 2016 reported modelled estimates for infectious diseases based on country of origin(19) (latent TB 19\%, parasitic infection 28\%, hepatitis B 5\%), which are similar to the observed rates in Camden.

Kent UASC 2016 data reported 41\% of UASC having psychological symptoms(19), substantially lower than the $77 \%$ in Camden UASC. Mental health needs in this study were subjectively assessed at the IHA with input from a CAMHS clinician. SDQ screening alone has been criticised for failing to identify the level of mental health need in this group(17), the Camden CAMHS team has recently replaced the SDQ with the RHS-15 Refugee Health Screener(20). $87 \%$ of Camden UASC were felt to meet the threshold for CAMHS involvement, a decision made with CAMHS input, suggesting that the close liaison with mental health services is justified.

The rates of reported physical assault/abuse are high in this study and half of young people had scars on examination consistent with these disclosures. The description of torture was used by one in six UASC, but there is an argument that all physical abuse or assault is a form of torture. Considering the known barriers to making a disclosure of sexual abuse/assault(21) this number in this cohort (13\% UASC, 38\% female UASC) is strikingly high. A further $6 \%$ denied personal sexual assault or abuse but described having witnessed or known of this happening to someone else. There is significant vicarious trauma of witnessing assault, but it 
is also recognised that children who feel unable to disclose their own abuse may describe this happening to another child(22). FGM is acknowledged to be a human rights violation; the horn of Africa, where many of the UASC come from, has some of the highest rates in the world. Documentation of physical evidence of torture or abuse, history of sexual assault/abuse and FGM may all have a significant impact on a young person's asylum claim. The IHA report should be made available to the young person in all cases, and they may choose to share this with their solicitors.

The barriers to engaging with services, including inconsistent names and dates of birth, and high DNA rates are consistent with other studies $(4,16)$. Face-to-face interpreters were used when possible, however, the interpreters had not received specific training and were not matched for gender of UASC. It is recognised that use of interpreters can be a barrier to UASC communicating their story(23), and that interpreters should be carefully selected if possible(24). Mistrust of health professionals is a significant barrier to understanding UASC health needs(16) and UASC may be wary of disclosing information, for example whether they are in contact with family at home, for fear that this might adversely affect their asylum claim. Many UASC also turn 18 soon after arrival, when they are discharged to primary care. A more flexible and individualised approach to transition to adult services could be very beneficial in this group. Unmet health need in adolescence is associated with poor health outcomes in adult life(25), and long-term outcomes are improved by early intervention and coordination of services. The study data demonstrates that consistent and coordinated attempts to re-engage can address some of these barriers and improve the attendance rate (from $60 \%$ to $85 \%$ ). 


\section{Next steps and policy recommendations}

Funding has been secured to implement a similar integrated pathway for UASC in a second borough and a prospective evaluation is underway. A qualitative study with UASC is also planned, aiming to explore their perceptions of existing services, what health needs are meaningful to them and the barriers to engaging with services.

An integrated pathway is in keeping with the proposed framework for best practice in management of newly arrived refugee children (comprehensive health screening, coordination of care, integration of physical, psychological and emotional needs, data collection and advocacy(26)). We demonstrated that the integrated pathway successfully addressed some of the barriers to engaging with services and demonstrates the potential to improve outcomes. Based on these data, this is an appropriate clinical approach for UASC in the UK. Given the high rates of infectious diseases diagnosed (41\%), we recommend universal asymptomatic screening of UASC arriving in the UK.

\section{CONCLUSION}

These results demonstrate that UASC are an extremely vulnerable population with identified high rates of infectious diseases, physical abuse/assault including torture, historical sexual abuse/assault and ongoing trafficking concerns. The majority of UASC require mental health support. Significant barriers were identified to engaging with services and initial follow-up attendance rates were low. As many of these young people were close to turning 18 there is a lack of data on longer-term outcomes or other follow-up recorded.

An integrated pathway has been successfully implemented and shown to deliver appropriate, joined-up care for UASC, consistent with current recommendations and further evaluation of 
16 | P a g e

the model is planned. If demonstrated to be successful, the integrated pathway for UASC could be adopted more widely and could change outcomes for this vulnerable population.

\section{Funding sources}

Alice Armitage is employed by UCL. Research at the UCL Great Ormond Street Institute of Child Health benefits from funding from the Great Ormond Street Hospital Biomedical Research Centre. No additional funding was available for this project. Authors declare no known conflicts of interest. 
Figure 1. - The integrated pathway for UASC

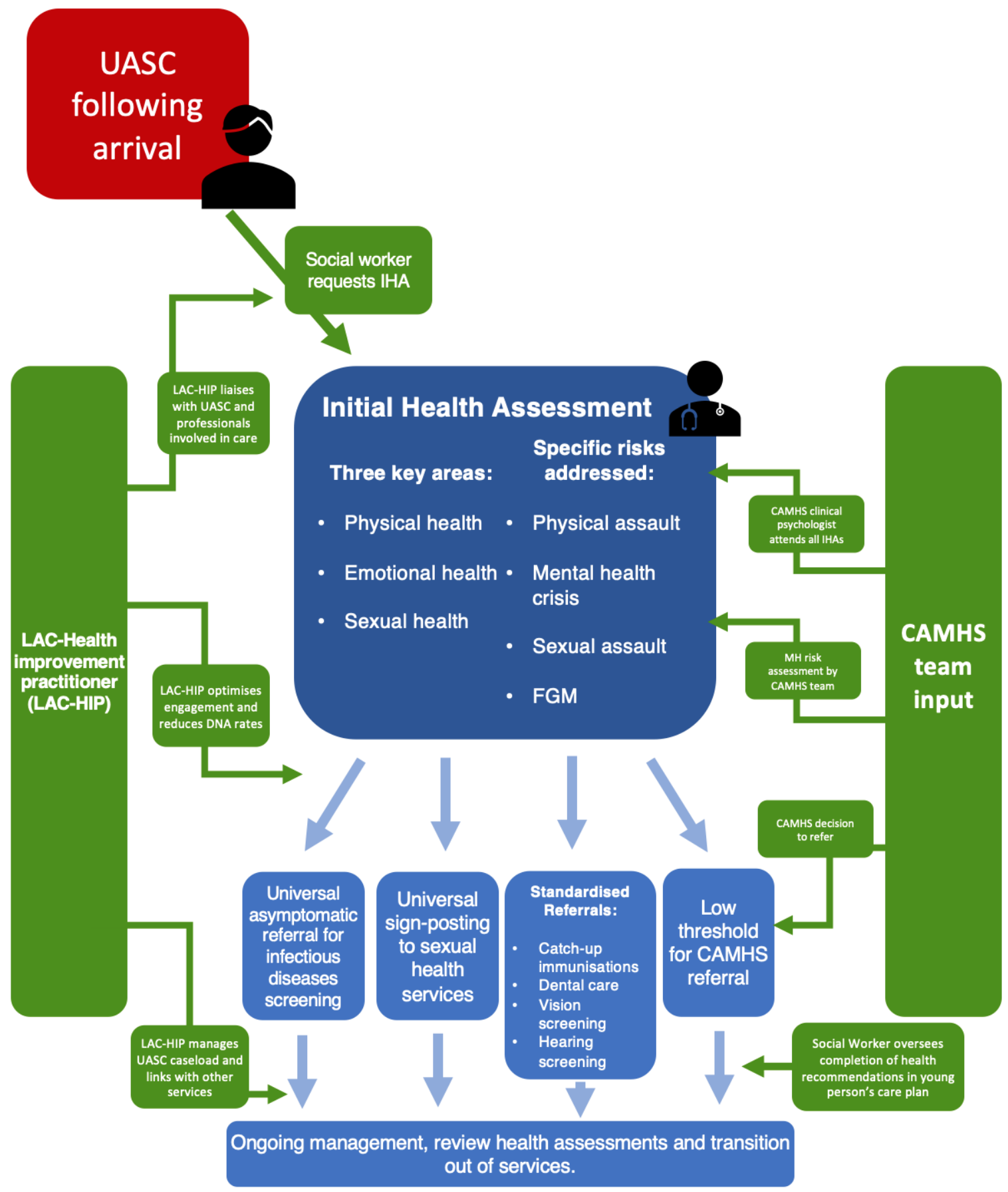

Table 1. - Clinical and demographic features reported at IHA

$\begin{array}{ll}\text { Clinical or demographic features } & \begin{array}{l}\text { Number/ number of Percentage } \\ \text { children with } \\ \text { available data }\end{array}\end{array}$




\begin{tabular}{|c|c|c|}
\hline Male & $85 / 101$ & $84 \%$ \\
\hline Age range (median, IQR) & $14-17(16,2)$ & \\
\hline Placed in foster care & $32 / 101$ & $32 \%$ \\
\hline $\begin{array}{l}\text { Placed in semi-independent } \\
\text { accommodation }\end{array}$ & $69 / 101$ & $68 \%$ \\
\hline \multicolumn{3}{|l|}{ Country of origin: } \\
\hline - Eritrea & $28 / 101$ & $28 \%$ \\
\hline - Sudan & $16 / 101$ & $16 \%$ \\
\hline - Ethiopia & $13 / 101$ & $13 \%$ \\
\hline - Vietnam & $9 / 101$ & $9 \%$ \\
\hline - Afghanistan & $8 / 101$ & $8 \%$ \\
\hline - Albania & $8 / 101$ & $8 \%$ \\
\hline - Morocco & $4 / 101$ & $4 \%$ \\
\hline - Syria & $3 / 101$ & $3 \%$ \\
\hline $\begin{array}{l}\text { - Other (Iran, Guinea, Algeria and } \\
\text { others) }\end{array}$ & $12 / 101$ & $12 \%$ \\
\hline Interpreter used (total) & $87 / 90$ & $97 \%$ \\
\hline - Face-to-face interpreter & $74 / 90$ & $82 \%$ \\
\hline - Phone interpreter & $10 / 90$ & $11 \%$ \\
\hline - Foster carer translating & $2 / 90$ & $22 \%$ \\
\hline \multicolumn{3}{|l|}{ Language spoken (where documented) } \\
\hline - Arabic & $22 / 80$ & $28 \%$ \\
\hline - Tigrinya & $22 / 80$ & $28 \%$ \\
\hline - Oromo & $9 / 80$ & $11 \%$ \\
\hline - Arabic & $9 / 80$ & $11 \%$ \\
\hline $\begin{array}{l}\text { Other (Kurdish, Farsi, French, } \\
\text { Pushto, Amharic) }\end{array}$ & $18 / 80$ & $23 \%$ \\
\hline Mean BMI percentile (SD) & $45.2(26.1)$ & \\
\hline $\begin{array}{l}\text { BMI percentile }<5 \% \text { centile } \\
\text { (underweight) }\end{array}$ & $3 / 95$ & $3 \%$ \\
\hline Inconsistent name & $13 / 101$ & $13 \%$ \\
\hline Inconsistent date of birth & $11 / 101$ & $11 \%$ \\
\hline Date of birth beginning 01/01 & $15 / 101$ & $15 \%$ \\
\hline
\end{tabular}

Table 2. - History of assault/abuse and examination findings

\begin{tabular}{|l|r|r|}
\hline History or examination finding & $\begin{array}{l}\text { Number/ } \\
\text { number of } \\
\text { children with } \\
\text { available data }\end{array}$ \\
\hline History of physical abuse/assault & $68 / 101$ & $67 \%$ \\
\hline History of torture & $16 / 101$ & $16 \%$ \\
\hline Scars consistent with disclosures & $55 / 101$ & $54 \%$ \\
\hline Evidence of harmful traditional practices & $9 / 101$ & $9 \%$ \\
\hline Disclosure of sexual abuse/assault & $13 / 101$ & $3 \%$ \\
\hline Disclosure of sexual abuse/assault (Female & $6 / 16$ & $38 \%$ \\
\hline UASC) & & $12 \%$ \\
\hline Suspicion of trafficking & $12 / 101$ & \\
\hline
\end{tabular}


Suspicion of trafficking (Female UASC)

$6 / 16$

Witnessed sexual abuse/assault

$6 / 101$

Table 3. - Infectious Diseases referrals, DNA rates and screening outcome

\begin{tabular}{|l|r|r|}
\hline ID referral characteristics & \multicolumn{2}{|l|}{$\begin{array}{l}\text { Number/ } \\
\text { number of } \\
\text { children with } \\
\text { available data }\end{array}$} \\
\hline DNA first appointment & $34 / 84$ & $40 \%$ \\
\hline Seen in paediatric ID clinic & $66 / 84$ & $78 \%$ \\
\hline Underwent ID screening in the trust* & $71 * * / 84$ & $85 \%$ \\
\hline $\begin{array}{l}\text { One or more positive result requiring } \\
\text { treatment }\end{array}$ & $28 / 69$ & $41 \%$ \\
\hline $\begin{array}{l}\text { Two or more positive results requiring } \\
\text { treatment }\end{array}$ & $9 / 69$ & $13 \%$ \\
\hline Common diagnoses & & $25 \%$ \\
\hline$-\quad$ Latent TB & $17 / 69$ & $13 \%$ \\
\hline$-\quad$ Schistosomiasis & $9 / 69$ & \\
\hline $\begin{array}{l}\text { Other parasitic infections } \\
\text { (Hookworm, Tapeworm, Giardia and }\end{array}$ & & $10 \%$ \\
\hline$\quad$ Trichuris) & $7 / 69$ & $6 \%$ \\
\hline - Hepatitis B & $4 / 69$ & \\
\hline
\end{tabular}

* Some following transition into adult services

** In two cases this fell outside the study period therefore data are not presented here

Table 4. - Sexual health screening outcome

\begin{tabular}{|l|r|r|}
\hline Sexual health referral characteristics & Numbers & Percentage \\
\hline DNA first appointment & $22 / 49$ & $49 \%$ \\
\hline Reported sexual activity & $14 / 41$ & $34 \%$ \\
\hline Sexual abuse/assault reported & $8 / 41$ & $20 \%$ \\
\hline Sexual health advice given & $37 / 41$ & $90 \%$ \\
\hline
\end{tabular}

\section{References}

1. National Statistics Children looked after in England including adoption: 2017 to 2018 [Internet]. Department for Education. 2018 [cited 13th December 2018]. Available from: https://www.gov.uk/government/statistics/children-looked-after-in-england-includingadoption-2017-to-2018.

2. Simmonds J, Merredew F. The Health Needs of unaccompanied Asylum seeking children and young people. British Association for Adoption and Fostering. NICE expert paper, EP23-LAC9; 2009.

3. Kadir A, Battersby A, Spencer N, Hjern A. Children on the move in Europe: a narrative review of the evidence on the health risks, health needs and health policy for asylum seeking, refugee and undocumented children. BMJ paediatrics open. 2019;3(1). 
4. Markova E, editor The situation of the unaccompanied minors migrants in the UK. Regional Conference on 'Migration of unaccompanied minors: acting in the best interest of the child', Torremolinos, Málaga-España; 2005.

5. Wade J, Mitchell F, Baylis G. Unaccompanied Asylum Seeking Children: The response of social work services. London: British Association for Adoption and Fostering (BAAF. 2005.

6. Eichler H. Improving statutory health assessments for looked after children. Nursing children and young people. 2011;23(3).

7. Derluyn I, Broekaert E, Schuyten G. Emotional and behavioural problems in migrant adolescents in Belgium. European child \& adolescent psychiatry. 2008;17(1):54-62.

8. Hjern A. Health of refugee and migrant children: Technical guidance. 2018.

9. Wade J. Preparation and transition planning for unaccompanied asylum-seeking and refugee young people: A review of evidence in England. Children and Youth Services Review. 2011;33(12):2424-30.

10. Kerbl R, Grois N, Popow C, Somekh E, Ehrich J. Pediatric healthcare for refugee minors in Europe: Steps for better insight and appropriate treatment. The Journal of pediatrics. 2018;197:323-4. e2.

11. Carballo M, Hargreaves S, Gudumac I, Maclean EC. Evolving migrant crisis in Europe: implications for health systems. The Lancet Global Health. 2017;5(3):e252-e3.

12. Portnoy S, Ward A. Unaccompanied asylum-seeking children and young people Understanding their journeys towards improved physical and emotional health. Clinical Child Psychology and Psychiatry. 2020;25(3):636-47.

13. Goodman R. Psychometric properties of the strengths and difficulties questionnaire. Journal of the American Academy of Child \& Adolescent Psychiatry. 2001;40(11):1337-45. 14. Ahmed A, Ayadi O'Donnell N, Wong M, Cohen J, Eisen S, Evanson R, et al. Developing an integrated health pathway for asylum seeking children: a holistic multiborough approach to caring for vulnerable unaccompanied minors in care. ISPCAN European Regional Meeting 20172017.

15. Hayes D. Keeping asylum seekers safe. Children and Young People Now. 2017;2017(16):15-.

16. Hayon TD, Oates J. The mental health service needs and experiences of unaccompanied asylum-seeking children in the UK: a literature review. Mental Health Practice. 2019;22(6).

17. Children's Society. Distress signals: Unaccompanied young people's struggle for mental health care. Author London, England; 2018.

18. Baauw A, Kist-van Holthe J, Slattery B, Heymans M, Chinapaw M, van Goudoever $\mathrm{H}$. Health needs of refugee children identified on arrival in reception countries: a systematic review and meta-analysis. BMJ Paediatrics Open. 2019;3(1):e000516.

19. Coyle RB, Samantha. Health Needs Assessment - Unaccompanied children seeking asylum. Kent Public Health Observatory, Council KC; 2016 March 2016.

20. The Adoption and Children (Coronavirus) (Amendment) Regulations 2020, (2020).

21. Crisma M, Bascelli E, Paci D, Romito P. Adolescents who experienced sexual abuse: Fears, needs and impediments to disclosure. Child abuse \& neglect. 2004;28(10):1035-48.

22. Hunter C, Brief N. Responding to children and young people's disclosures of abuse. 2011.

23. Jonzon R, Lindkvist P, Johansson E. A state of limbo-in transition between two contexts: Health assessments upon arrival in Sweden as perceived by former Eritrean asylum seekers. Scandinavian journal of public health. 2015;43(5):548-58.

24. Hopkins P, Hill M. The needs and strengths of unaccompanied asylum-seeking children and young people in Scotland. Child \& Family Social Work. 2010;15(4):399-408. 
25. Hargreaves DS, Elliott MN, Viner RM, Richmond TK, Schuster MA. Unmet health care need in US adolescents and adult health outcomes. Pediatrics. 2015;136(3):513-20.

26. Woodland L, Burgner D, Paxton G, Zwi K. Health service delivery for newly arrived refugee children: a framework for good practice. J Paediatr Child Health. 2010;46(10):560-7. 